Check for updates

Cite this: Phys. Chem. Chem. Phys., 2020, 22, 25502

Received 1st October 2020 Accepted 27th October 2020

DOI: $10.1039 / \mathrm{d} 0 \mathrm{cp} 05172 \mathrm{a}$

rsc.li/pccp

\title{
Towards understanding the catalytic properties of lead-based ballistic modifiers in double base propellants $\dagger$
}

\author{
Lisette R. Warren, Colin R. Pulham (D) and Carole A. Morrison (D)*
}

\begin{abstract}
Lead-based ballistic modifiers are additives in double base propellants (DBPs) which render the burn rate insensitive to changes in pressure within a defined pressure range, thus imparting greater control of combustion conditions. In-coming European legislation will soon ban the use of lead in propellant formulations, however, and few suitable candidate replacement materials are currently available. In an effort to understand better the unique properties offered by lead-based modifiers, we present a firstprinciples computational study on $\mathrm{Pb}, \mathrm{PbO}, \mathrm{PbO}_{2}, \mathrm{SnO}_{2}$ and $\mathrm{Bi}_{2} \mathrm{O}_{3}$, all of which have been investigated experimentally as ballistic modifier materials. Our study demonstrates that various quantifiable properties exist for the lead-based materials. Overall, they have narrower electronic band gaps, lower surface energies and lower surface work functions than the lead-free systems, indicating a greater propensity to form stable chemical surfaces with higher catalytic activity. We also show that of the set, only $\mathrm{Pb}$ and $\alpha-\mathrm{PbO}$ can support the formation of a weakly bound layer of amorphous carbon, a key experimental observable in the burning of DBPs.
\end{abstract}

\section{Introduction}

Double base propellants (DBPs) are a form of solid rocket propellant consisting of the nitrate esters nitrocellulose (40-70\%), and nitroglycerin (15-41\%, see Fig. 1), which bind together to form a polymeric gel. This mixture acts as a combined fuel and oxidiser, and finds application in missile and rocket propulsion due to the rapid release and expansion of smokeless gaseous combustion products. ${ }^{1,2}$

The burning rate $r$ for DBPs is represented by Vieille's law, according to:

$$
r=a p^{n}
$$

where $a$ is a constant dependent on the chemical composition and the initial propellant temperature, $p$ is the combustion chamber pressure, and $n$ is the pressure exponent of the burning rate. ${ }^{1,3}$ For DBPs $n$ is non-zero, such that the burn rate is significantly dependent on pressure, which leads to instabilities in the performance of rocket motors. ${ }^{2}$ This has been counteracted by additives, termed ballistic modifiers or burn-rate catalysts, which alter the burning behaviour of the propellant in three distinct ways, as summarised in Fig. 2.

EaSTCHEM School of Chemistry, University of Edinburgh, The King's Buildings, David Brewster Road, Edinburgh, EH9 3FJ, UK. E-mail: C.Morrison@ed.ac.uk $\dagger$ Electronic supplementary information (ESI) available. See DOI: 10.1039/ d0cp05172a

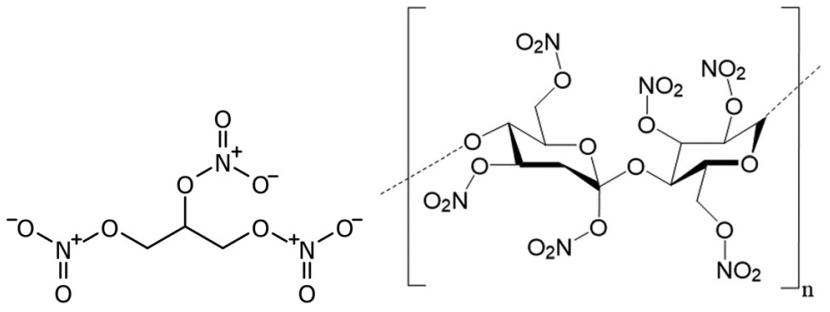

Fig. 1 Structures of nitroglycerin [left] and fully-nitrated nitrocellulose, $14.4 \% \mathrm{~N}$ by weight [right]

First, in the low-pressure range the ballistic modifier catalyses the burn rate to substantial rates, in a process termed superrate burning. ${ }^{5,6}$ Second, as the pressure increases, the superrate burning rapidly disappears to produce either a plateau burn rate with a low-pressure index $(0<n<0.2)$, or a decrease in burn rate where the pressure index drops below zero; the latter phenomenon is termed mesa-rate burning..$^{2,3,7}$ Finally, at higher pressures, the burn rate returns to approximately the level of the unmodified propellant.

The first ballistic modifiers were identified during World War Two, when researchers serendipitously discovered that the use of lead-containing lubricants in the propellant manufacturing process lead to a greatly increased pressure exponent in the ambient pressure region. ${ }^{3}$ Lead-based ballistic modifiers are commonly used in the form of lead salts of organic acids such 


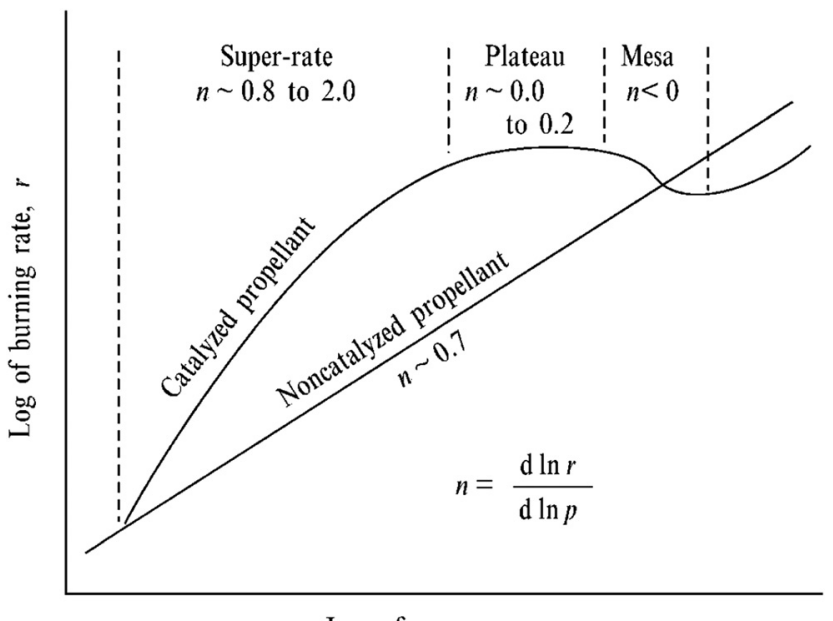

Log of pressure, $p$

Fig. 2 Burning rate-pressure relation for non-catalysed and catalysed DBP. ${ }^{8}$ Copyright (1974) AIAA.

as lead acetate, lead salicylate and lead $\beta$-resorcylate, or as the oxides $\mathrm{PbO}, \mathrm{Pb}_{3} \mathrm{O}_{4}$ and $\mathrm{PbO}_{2} \cdot{ }^{8-12}$ To date, only these lead-based compounds support all three burn-rate effects, while the inclusion of other additives, such as copper-based products and carbon black, have been found to further increase the catalytic effect of the lead salts. ${ }^{2,12-14}$

The on-going dependence on lead is problematic as this highly toxic element presents hazards in its use and disposal, and impending European Union regulations (Reach - Registration, evaluation, authorisation and restriction of chemicals) ${ }^{15}$ will ban their use. Hewkin et al. tested a wide range of alternative modifiers including $\mathrm{CuO}, \mathrm{Fe}_{2} \mathrm{O}_{3}, \mathrm{ZnO}, \mathrm{Co}_{2} \mathrm{O}_{3}$ and $\mathrm{SnO}_{2}$ which, while increasing the combustion rate, could not support plateau burning. ${ }^{11}$ In particular, $\mathrm{CuO}$ and $\mathrm{SnO}_{2}$ have been found to produce extensive super-rate burning at low pressures, but fail to plateau off the burn rate as the pressure increases. A recent review on current ballistic modifiers, which documents the trends towards nano-scale particles of ballistic modifiers, maintains the dependence on lead to generate plateau burning. ${ }^{16} \mathrm{Nano}-\mathrm{Bi}_{2} \mathrm{WO}_{6}$ was recently reported as a promising lead-free alternative capable of achieving plateau burning, however this was observed at a considerably higher pressure range than for the lead-based modifiers which may limit its application, and no mesa effect was observed. ${ }^{17}$

In order to understand how ballistic modifiers alter the burn-rate of DBPs, the decomposition mechanism should be considered. Much of the experimental work and theory development was documented in the 1950s-1990s, and has recently been summarised in a review article. ${ }^{18}$ It is known that combustion of DBPs occurs in a succession of distinct zones, as depicted in Fig. 3. 3,11 Initially the temperature rises in the conductive heat zone until thermal degradation of the DBP is significant, wherein the nitrate esters decompose (reversibly) to $\mathrm{RO}^{\bullet}$ and $\mathrm{NO}_{2}$ just below the burning surface. A series of simultaneous secondary reactions then occur to deliver primarily aldehyde and $\mathrm{NO}_{2}$ fragments to the burning surface. Burning surface temperatures are typically on the order of $300{ }^{\circ} \mathrm{C}$, and do not exceed $500{ }^{\circ} \mathrm{C}^{7}$ Highly exothermic gaseous oxidation and reduction reactions then occur in the fizz zone, and the temperature rapidly increases. A variety of products are produced, primarily $\mathrm{NO}, \mathrm{CO}, \mathrm{CO}_{2}$ and $\mathrm{H}_{2} \mathrm{O} .{ }^{19}$ Temperatures at the end of the fizz zone are typically $800-1000{ }^{\circ} \mathrm{C}$. Redox reactions of these products in the next zone (the dark zone) takes place slowly unless the pressure is particularly high. This is then followed by the flame zone, where the final combustion products of $\mathrm{N}_{2}, \mathrm{CO}_{2}, \mathrm{CO}$ and $\mathrm{H}_{2} \mathrm{O}$ are formed, and a luminous flame is produced.

From the perspective of DBP decomposition in the presence of ballistic modifiers, there is consensus in the literature that catalysis takes place in the fizz zone, and therefore involves reactions to produce $\mathrm{NO}_{2}$ and aldehyde fragments, and to

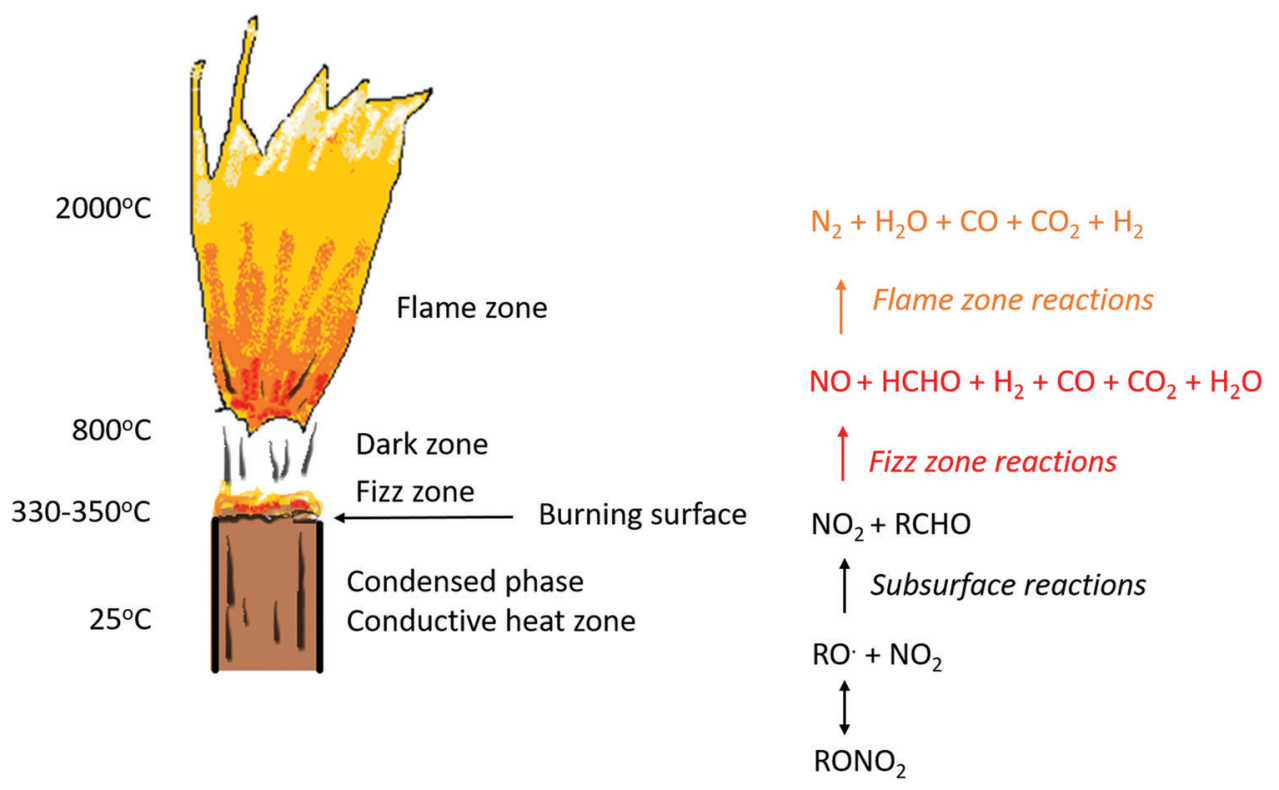

Fig. 3 Schematic diagram of the flame regions in the DBP combustion zone. Reproduced from ref. 18 with permission from Wiley. 
support potential reduction/oxidation reactions, in these respective parts of the flame. ${ }^{5,6,9,20,21}$ A thermochemical study in 1984 showed that a large variety of lead salts all decompose within the temperature range of $300-500{ }^{\circ} \mathrm{C}$, which is consistent with temperatures just below the burning surface. ${ }^{10}$ It is therefore likely that the catalytically active form of the ballistic modifier will be a decomposition product of the lead salts. Furthermore $\mathrm{PbO}$ and $\mathrm{PbO}_{2}$ have been directly proven to be capable of produce plateau burning, ${ }^{11,12,22}$ whilst mass spectrometry studies have identified that $\mathrm{Pb}, \mathrm{PbO}, \mathrm{PbO}_{2}, \mathrm{H}_{3} \mathrm{PbO}_{4}$ and elemental carbon are all formed in the decomposition of lead ballistic modifiers within the combustion process. ${ }^{9}$ Of the different lead oxide species, $\mathrm{PbO}$ is widely regarded as the most stable form, ${ }^{23}$ and so it is likely that other forms of lead oxide will convert to this in the combustion flame.

Notable to the catalytic decomposition of DBPs is the observation that the addition of carbon black alongside lead salts significantly improves the initial super-rate burning and plateau burning rates. Furthermore, the existence of a carbon matrix at the burning surface in the presence of lead salts has been identified in many experiments. ${ }^{5,7,9,11,24-26}$ A compelling catalytic theory for the decomposition of DBPs with ballistic modifiers is that the initial formation of this carbon soot layer is responsible for modifying the burning surface and aiding super-rate burning; the subsequent loss of the carbon matrix with increasing pressure has then been proposed for inducing the plateau-burning effect. ${ }^{11,18,27}$

As the available experimental evidence points towards the ballistic modifier decomposing to catalytically active clusters interacting at a solid/gas interface, a computational modelling investigation into the surface properties of various metal and metal oxides surfaces can offer fundamental insight into the nature of these catalytic processes. To this end, herein we simulate the electronic properties of the bulk crystalline materials of $\mathrm{Pb}, \mathrm{PbO}$ and $\mathrm{PbO}_{2}$, which have demonstrated success as burn-rate modifiers when added to DBP formulations, and compare against $\mathrm{Bi}_{2} \mathrm{O}_{3}$ and $\mathrm{SnO}_{2}$ which, while capable of accelerating reactions at low gas pressures, have failed to support plateau or mesa burning effects. ${ }^{11,12}$ This study seeks to identify the likely surfaces that will form in the condensed phase and to compute various chemical reactivity markers, namely electronic band gaps, surface energies and surface work functions, which may help explain the differences in chemical reactivity. A layer of amorphous carbon has been deposited onto each model to investigate its propensity to support a carbon layer. In this way we identify some unique properties of the lead-based systems, in the hope that these metrics will accelerate the search for non-toxic ballistic modifier replacements.

\section{Results and discussion}

\section{Structure and electronic properties of bulk models}

In order to investigate the catalytic properties of lead-based ballistic modifiers, condensed phase models of $\mathrm{Pb}, \mathrm{PbO}$ and $\mathrm{PbO}_{2}$ have been investigated. $\mathrm{SnO}_{2}$ and $\mathrm{Bi}_{2} \mathrm{O}_{3}$ have also been studied to provide a comparison with lead-free alternatives, which while known to support super-rate burning, fail to achieve the plateau and mesa rate effects.

As the temperature of the burning surface in DBPs does not exceed $500{ }^{\circ} \mathrm{C},{ }^{7}$ the phase of the bulk model to be considered should be stable under these conditions. For PbO there are two known stable phases: litharge $\alpha$-PbO (space group $P 4 / \mathrm{nmm}$ ) is the ambient temperature structure, which transitions to massicot $\beta-\mathrm{PbO}$ (space group $\mathrm{Pbcm}$ ) at temperatures above $500{ }^{\circ} \mathrm{C}^{28-30}$ As this is within the limit of the burning surface temperature, both phases of $\mathrm{PbO}$ have been included in this study. Both are characterised by layers orthogonal to either the $c$ - $(\alpha$-PbO) or $a$-axis $(\beta$-PbO), wherein all oxygen atoms are sandwiched between two Pb sub-layers (see Fig. 4). For both systems inter-layer spaces are occupied by the lone pairs on $\mathrm{Pb}(\mathrm{II})$. For $\mathrm{PbO}_{2}, \alpha-\mathrm{PbO}_{2}$ is known to transform into $\beta-\mathrm{PbO}_{2}$ at room temperature and under ambient humidity conditions, ${ }^{29}$ whereas the reverse transition appears to only occur at high

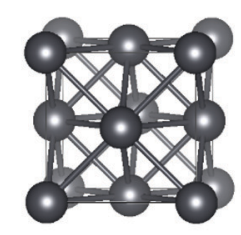

Elemental $\mathrm{Pb}(F m \overline{3} m)$

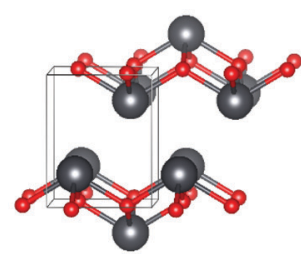

$\alpha-\mathrm{PbO}(\mathrm{P} 4 / \mathrm{nmm})$

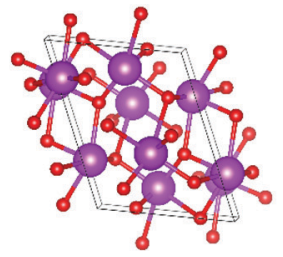

$\alpha-\mathrm{Bi}_{2} \mathrm{O}_{3}(P 21 / c)$

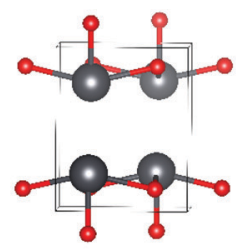

$\beta-\mathrm{PbO}(\mathrm{Pbcm})$

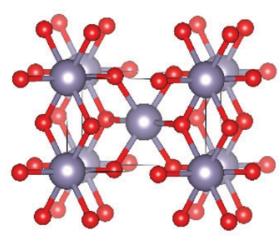

$\mathrm{SnO}_{2}(P 42 / m n m)$

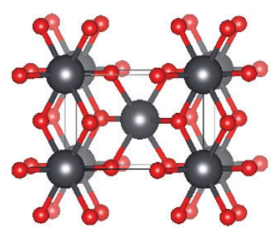

$\beta-\mathrm{PbO}_{2}\left(P 4_{2} / m n m\right)$

Fig. 4 Structures of bulk models of lead-based (top) and lead-free (bottom) ballistic modifiers investigated in this study. Space group is in paranthesis. Colour scheme: red $(\mathrm{O})$, dark grey $(\mathrm{Pb})$, purple $(\mathrm{Bi})$, and light grey $(\mathrm{Sn})$. 
pressure. ${ }^{29}$ Thus, only the $\beta$-form (space group $P 4_{2} / \mathrm{mnm}$ ) is considered in this study. The most stable phase for $\mathrm{SnO}_{2}$ (stable up to $800{ }^{\circ} \mathrm{C}$ and high pressures) ${ }^{31}$ is isostructural with $\beta-\mathrm{PbO}_{2}{ }^{32}$ Unlike in $\mathrm{PbO}$, the $\mathrm{Pb} / \mathrm{Sn}$ (Iv) metal atoms are fully coordinated to oxygen atoms, resulting in an absence of metalbased lone pairs in these structures. Bismuth oxide has four known crystal phases ( $\alpha$-, $\beta$-, $\gamma$ - and $\delta$-); this study focuses on the monoclinic $\alpha$-form (space group $P 2_{1} / c$ ), ${ }^{33}$ which is the most stable phase up to $1000 \mathrm{~K}^{34}$ To complete the study, we also include metallic lead, which has a face-centered cubic lattice (space group $F m \overline{3} m$ ), consisting of four atoms in the unit cell. Images of the bulk crystalline structures studied in this work are presented in Fig. 4.

Input structures were taken from the ICSD, with calculations performed as described in the Computational Methods section. In order to interpret the electronic behaviour of the bulk models, the electronic band structure and projected density of states (PDOS) onto atomic orbitals were calculated (Fig. 5 and 6). A variety of functionals were tested; the hybrid HSE06 functional performed very well for semiconducting systems, and the GGA PBE functional performed best for metallic $\mathrm{Pb}$. Full details of the optimised structures are recorded in the ESI; $\dagger$ for all models reported in the main text the optimised unit cell volumes deviated from the experimental values by no more than $2.5 \%$. Due to the layered nature of the $\mathrm{PbO}$ models, lattice parameters have not been optimised for these models, as attempts to account for dispersion interactions via the Grimme D3 dispersion correction scheme did not result in a satisfactory unit cell optimisation (see ESI $\dagger$ ). Similarly, for $\alpha-\mathrm{Bi}_{2} \mathrm{O}_{3}$, the correction scheme resulted in severe over-binding of the $b$-axis, and so unit cell optimisation without dispersion was pursued for this model.

It is evident from Fig. 5 that the electronic band gaps of the lead-based materials are generally smaller than for the non-lead oxides. $\mathrm{Pb}$ is, as expected, metallic, whilst $\beta-\mathrm{PbO}_{2}$ is a semimetal with a small band gap, in agreement with both experimental reports ${ }^{35,36}$ and other DFT calculations. ${ }^{35}$ Both $\alpha$ - and $\beta$-PbO are semiconductors, with the $\alpha$-form presenting a smaller indirect band gap of $1.78 \mathrm{eV}$, in direct agreement with both experiment $^{37,38}$ and computation. ${ }^{39}$ The $\beta$-form of $\mathrm{PbO}$ presents a computed band gap of $2.89 \mathrm{eV}$ with the HSE06 functional, compared to an empirical value of $2.6-2.7 \mathrm{eV} .^{38,40}$ The electronic structure for $\alpha-\mathrm{Bi}_{2} \mathrm{O}_{3}$ (band gap $3.23 \mathrm{eV}$ ) is close to previous calculations reported for the PBE functional $(2.8 \mathrm{eV})^{41}$ and is similar to experimental values $(2.5-2.8 \mathrm{eV}) .{ }^{42,43}$ Finally, $\mathrm{SnO}_{2}$ is found to be a direct band gap insulator; experimental data reports a direct transition of $3.56 \mathrm{eV},{ }^{44}$ and our simulation matches a previous report using the same functional $(2.8 \mathrm{eV}) .{ }^{45}$ Thus, even though $\mathrm{PbO}_{2}$ and $\mathrm{SnO}_{2}$ are isostructural and present very similar electronic structures, the band gap for $\mathrm{PbO}_{2}$ is significantly shorter compared to $\mathrm{SnO}_{2}$. This can be attributed to relativistic effects: while in both cases the metal s-states form the lower conduction band, the $\mathrm{Pb} 6 s$ states reside much lower in energy than the $5 \mathrm{~s}$ Sn states, thereby narrowing the band gap. ${ }^{46}$

Further detail into the electronic nature of the valence band maximum (VBM) and conduction band minimum (CBM) can be gathered from the projected densities of states in Fig. 6 . Comparing the lead-based systems first, the $6 \mathrm{p}$ states dominate the VBM near the Fermi level for $\mathrm{Pb}$, where $(6 \mathrm{p})^{2}$ forms the outermost valence electrons. Both $\alpha$ - and $\beta$-PbO present very similar density contributions around the Fermi level; their electronic nature differs only in the magnitude of the band gap. Compared to $\mathrm{Pb}$, in $\mathrm{PbO}$ the unoccupied $\mathrm{Pb}$ p-states now shift to the CBM. The valence bands are constructed from hybridised $\mathrm{O}$ p-states and $\mathrm{Pb}$ s- and $\mathrm{p}$-states; the nature of this interaction has been discussed in detail by Walsh et al. ${ }^{47}$ and is used to account for the formation of the asymmetric lone pair on $\mathrm{Pb}$ (II) in litharge $\alpha$-PbO. Further oxidation to $\beta-\mathrm{PbO}_{2}$ now results in the unoccupied metal $6 \mathrm{~s}$ state forming the major contribution to the CBM. Oxygen p-states now dominate the valence band edge, with a very minor contribution from the metal d-states. Thus, each of the lead-based systems ( $\mathrm{Pb}, \mathrm{PbO}$ and $\mathrm{PbO}_{2}$ ) present different orbital contributions around the Fermi surface, and can be considered to be chemically distinct, while overall presenting relatively small electronic band gaps.

For the lead-free materials, $\mathrm{Bi}$ is found in oxidation state(III) in $\alpha-\mathrm{Bi}_{2} \mathrm{O}_{3}$, and therefore presents the same valence electron count as $\mathrm{Pb}$ (II) in $\alpha$-PbO. Thus, very similar electronic contributions are observed around the Fermi surface, where interaction between the Bi 6s-states, O 2p-states, and unoccupied Bi 6p-states have also been identified to be responsible for the presence of an asymmetric lone pair. ${ }^{46} \mathrm{SnO}_{2}$ is isostructural to $\mathrm{PbO}_{2}$, such that electronic contributions to the VBM and CBM are very similar for the two systems (see Fig. 6).

From these simulations, a trend emerges that the electronic band gap, which is a metric of chemical reactivity, is smaller for the Pb-based systems than for the lead-free systems. For all metal oxide models, the $\mathrm{O} 2 \mathrm{p}$ states dominate the valence band maximum, with contributions from metals varying depending on their oxidation state.

\section{Properties of bare surfaces}

$2 \mathrm{D}$ periodic slabs were generated to study the surface properties of the lead-based and lead-free models (see Computational methods). Atomic relaxations only were considered, and features such as surface reconstructions and defect formation effects were not included. While this may lack authenticity with the experimental observation of e.g. flow of powders (where high surface energies may be indicative of materials that clump), it can provide valuable insights into their stabilities at point of formation in a hot gas stream. Surface energies are used to understand the chemical stability of the surfaces, as well as the structural nature of each surface, while surface work functions indicate the energy required to oxidise the material, and therefore provide another metric for chemical reactivity. Structures for the other (less stable) studied surfaces with relaxed surface energies are reported in the ESI. $\dagger$

Ball-and-stick models of the most stable surface for each system are shown in Fig. 7. Computed surface energies and work functions are presented for both the hybrid HSE06 functional and GGA PBE functional in Table 1. We note that surface energies computed by the HSE06 hybrid method are generally 


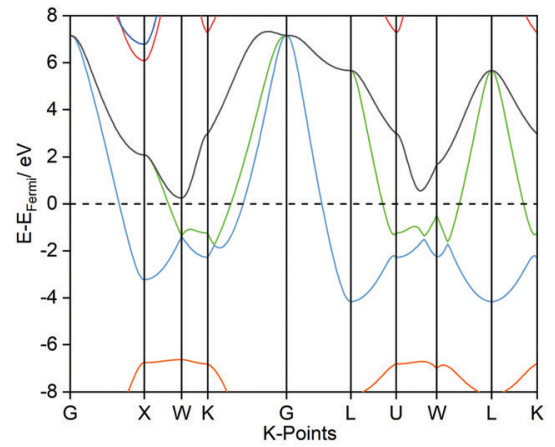

$\mathrm{Pb}$ (PBE-D3)

Computed band gap: metallic

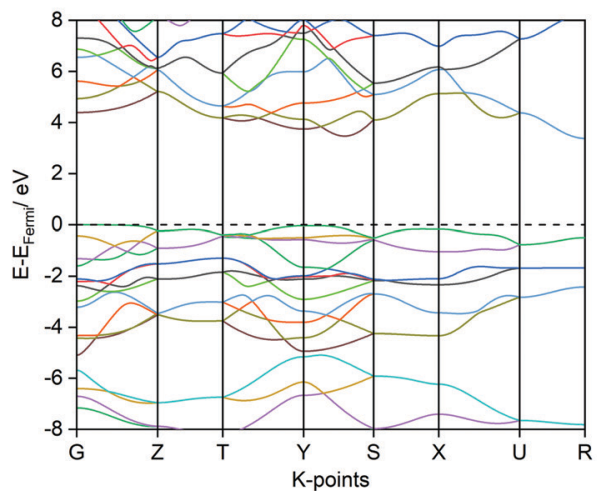

$\beta$-PbO (HSE06-D3)

Computed band gap : $2.89 \mathrm{eV}$

Experiment: 2.6-2.7 eV38,40

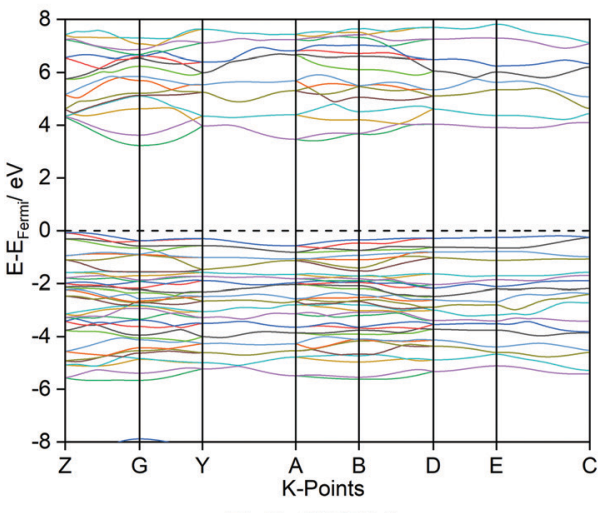

$\alpha-\mathrm{Bi}_{2} \mathrm{O}_{3}$ (HSE06)

Computed band gap: 3.23

Experiment: 2.5-2.8 42,43

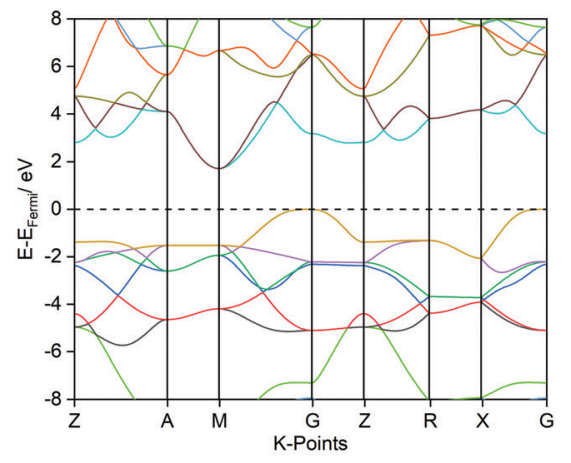

$\alpha$-PbO (HSE06-D3)

Computed band gap: $1.78 \mathrm{eV}$

Experiment: $1.9 \mathrm{eV}^{37,38}$

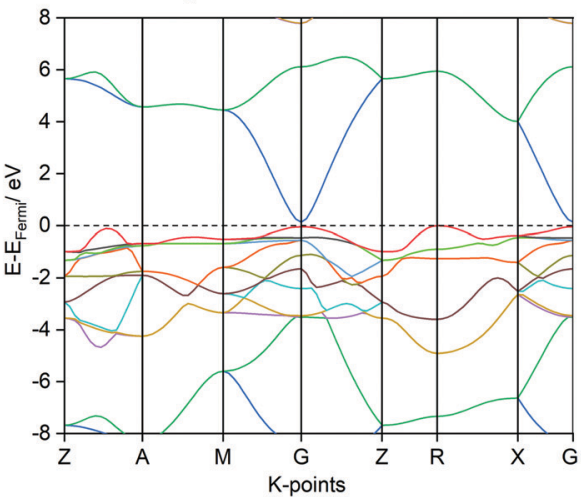

$\beta-\mathrm{PbO}_{2}$ (HSE06-D3)

Computed band gap: $0.13 \mathrm{eV}$

Experiment: $0.61 \mathrm{eV}^{36}$ (indirect)

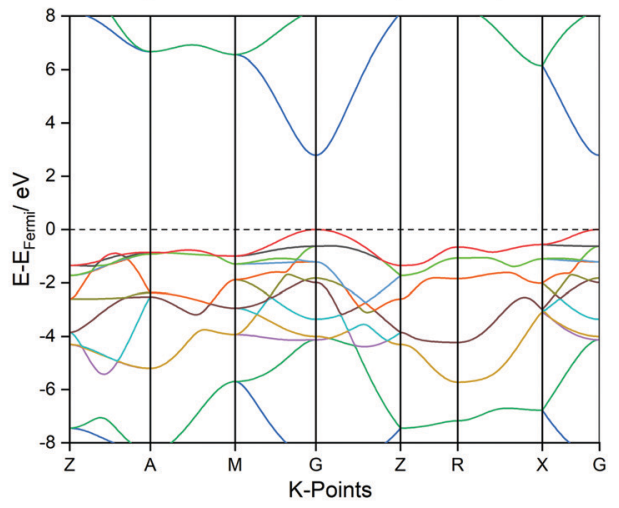

$\mathrm{SnO}_{2}$ (HSE06-D3)

Computed band gap: 2.78

Experiment: 3.56 44,48

Fig. 5 Computed band structures and band gaps for the best fitting functional for each of the lead-based and non-lead systems. Experimental band gaps also given.

greater than those obtained for the GGA PBE method. For all systems, the computed band gap of the surface is smaller than that of the bulk system (see Table 1 and Fig. 5). As with the bulk systems, a similar trend is observed where the Pb-based systems portray smaller band gaps than the Pb-free modifiers, which again suggests a more chemically reactive state. The nature of the VBM and CBM is the same as observed for the bulk models. For all surfaces, the electron density around the band gap is located largely on the exposed surface states due to the increasing chemical activity of the unsaturated valency sites (see $\mathrm{ESI} \dagger$ ).

From the perspective of forming clusters in the condensed phase of DBPs, low values for the surface energy indicate chemical stability of the surface and ease of formation, while 


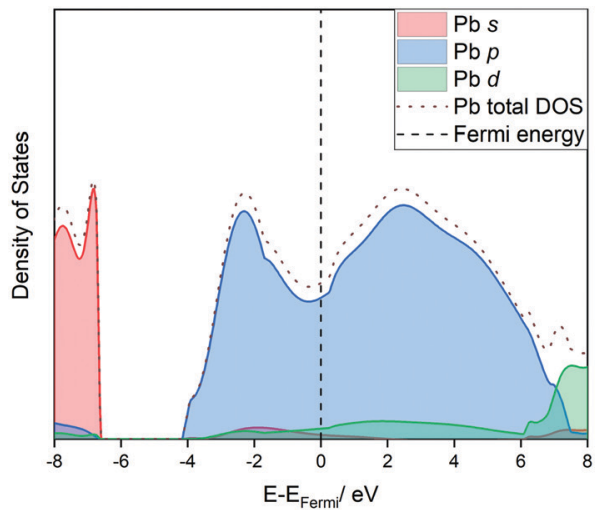

$\mathrm{Pb}$ (PBE-D3)

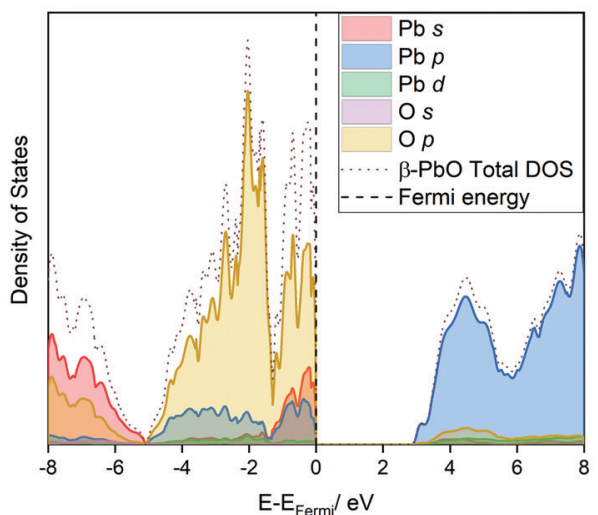

$\beta-\mathrm{PbO}(\mathrm{HSE06}-\mathrm{D} 3)$

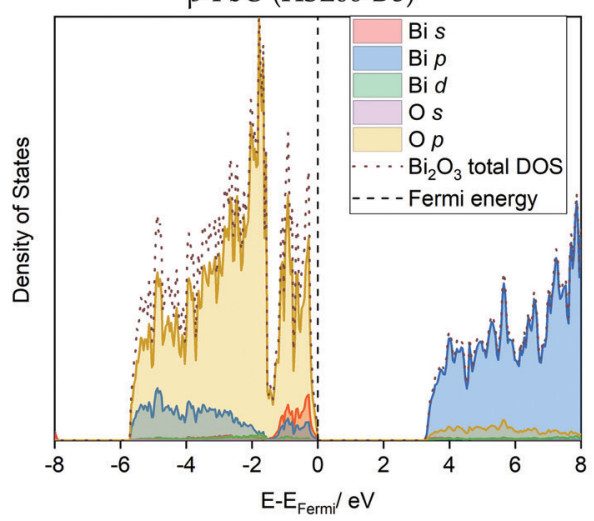

$\alpha-\mathrm{Bi}_{2} \mathrm{O}_{3}(\mathrm{HSE} 06)$

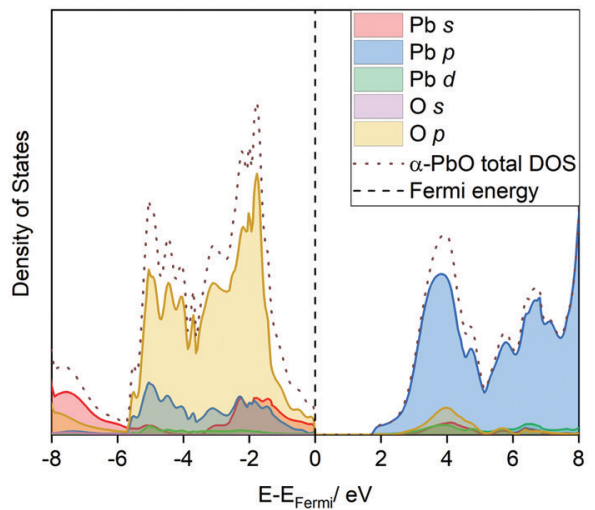

$\alpha$-PbO (HSE06-D3)

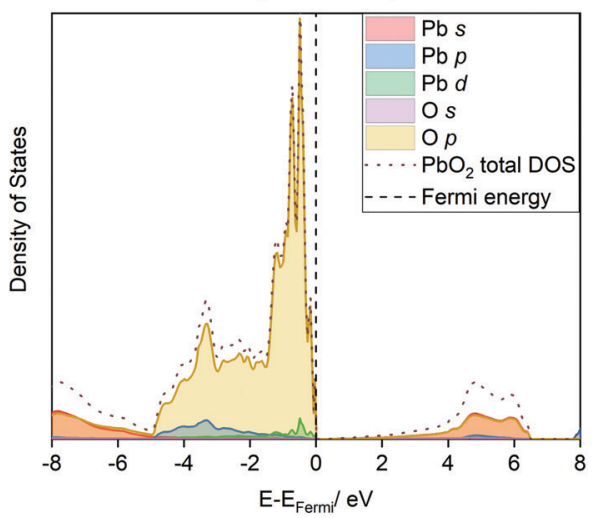

$\beta-\mathrm{PbO}_{2}(\mathrm{HSE06}-\mathrm{D} 3)$

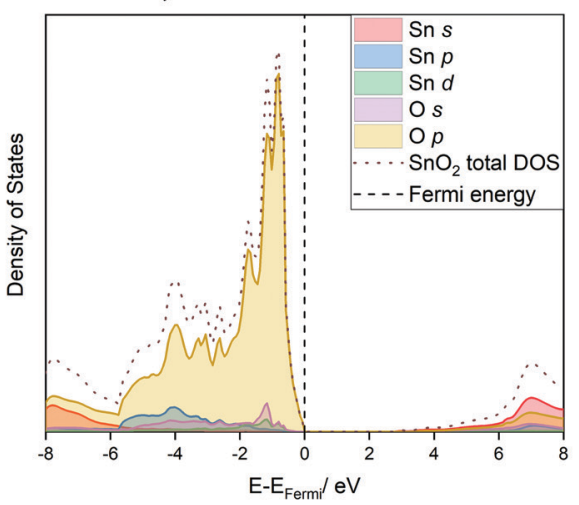

$\mathrm{SnO}_{2}$ (HSEO6-D3)

Fig. 6 Computed density of states for the best fitting functional for the lead-based and non-lead systems.

higher values indicate an energetic barrier to formation and a higher propensity to form larger clusters. From this study, it is notable that the $\mathrm{Pb}$-based surfaces all present relatively low surface energies for formation, which in turn suggests a comparative ease for these compounds to form small clusters with stable faces. The (111) surface of $\mathrm{Pb}$ was deduced to be the most stable, as expected for a fcc metal. ${ }^{56}$ For $\alpha$-PbO and $\beta$-PbO the (001) and (100) surfaces, respectively, which arise due to the breaking of weak van der Waals interactions between the layers, were found to be the most stable, in agreement with previous reports (on isostructural $\mathrm{SnO}$ ) ${ }^{57}$ and $\beta$-PbO. ${ }^{53}$ For $\beta-\mathrm{PbO}_{2}$ and
$\mathrm{SnO}_{2}$, the (110) surface was deduced to be the most stable, in agreement with other DFT calculations reported for isostructural rutile $\mathrm{TiO}_{2},{ }^{58-60}$ which has also been verified experimentally. ${ }^{61}$ Due to breaking of $\mathrm{Pb}-\mathrm{O}$ bonds, $\beta-\mathrm{PbO}_{2}(110)$ has a noticeably higher surface energy for formation compared to the other lead systems. Isostructural $\mathrm{SnO}_{2}$, in turn, presents a much higher surface energy value, attributed to the severance of stronger $\mathrm{Sn}-\mathrm{O}$ bonds compared to $\mathrm{Pb}-\mathrm{O} .^{62}$ Thus, $\mathrm{SnO}_{2}$ presents the highest surface energies for formation in the test set, and therefore a greater propensity to form particles of larger diameter to minimise the surface/volume ratio. This particle agglomeration effect 


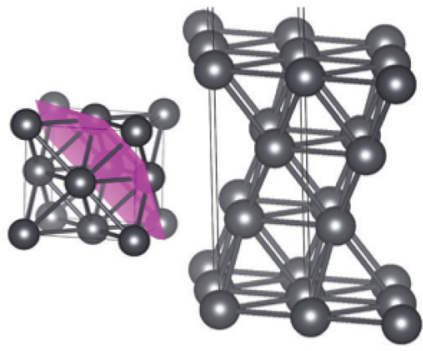

$\mathrm{Pb}(111)-\mathrm{Pb}$

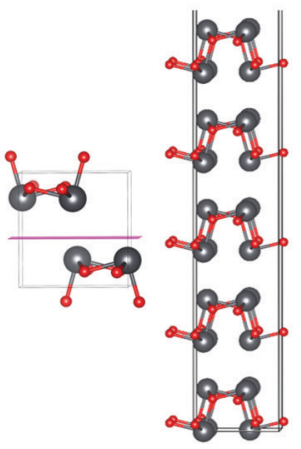

$\beta-\mathrm{PbO}(100)-\mathrm{Pb}$

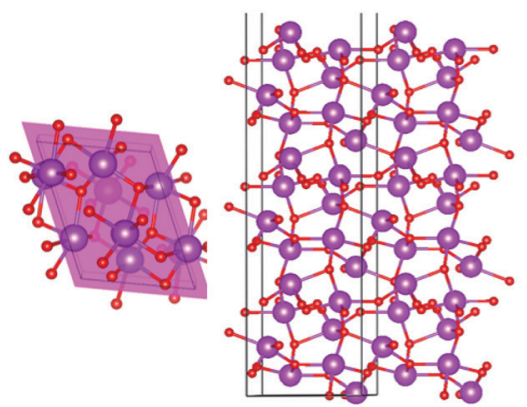

$\alpha-\mathrm{Bi}_{2} \mathrm{O}_{3}(010)-\mathrm{O}$

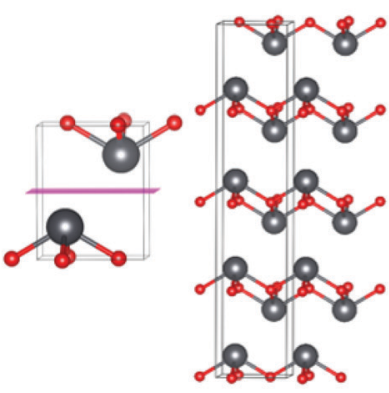

$\alpha-\mathrm{PbO}(001)-\mathrm{Pb}$

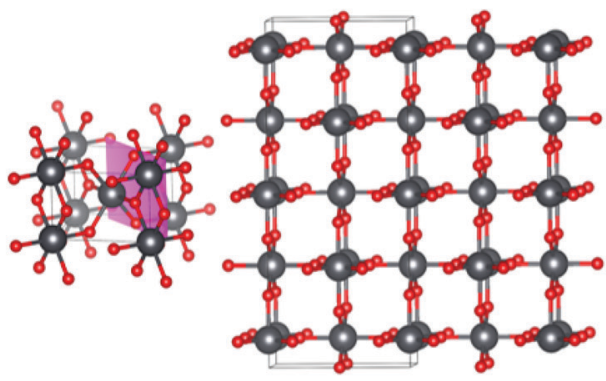

$\beta-\mathrm{PbO}_{2}(110)-\mathrm{O}$

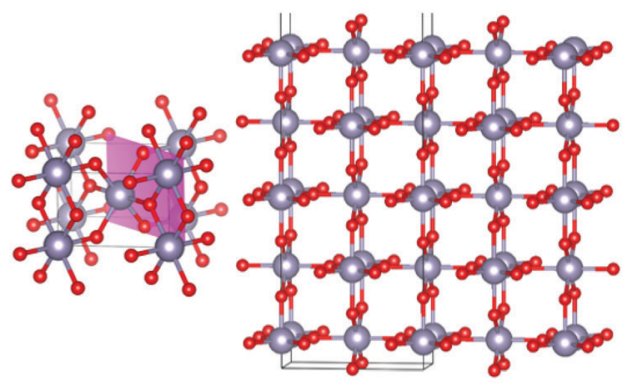

$\mathrm{SnO}_{2}(110)-\mathrm{O}$

Fig. 7 Ball-and-stick models of most stable surface for each studied system as indicated; expanded for visualisation. Surfaces are 2D periodic models, with no directionality along $z$-direction. Colour scheme: red $(\mathrm{O})$, dark grey $(\mathrm{Pb})$, purple (Bi), and light grey $(\mathrm{Sn})$.

Table 1 Summary of surface band gaps, surface energies $(\gamma)$ and surface work functions $(\varphi)$ for the lead and non-lead systems

\begin{tabular}{lllllll}
\hline System & Band gap $(\mathrm{eV})$ & $\gamma\left(\mathrm{J} \mathrm{m}^{-2}\right) \mathrm{HSE} / \mathrm{PBE}$ & Other works $\gamma\left(\mathrm{J} \mathrm{m}^{-2}\right)$ & $\varphi(\mathrm{eV}) \mathrm{HSE} / \mathrm{PBE}$ & Other works $\varphi(\mathrm{eV})$ & Expt $\varphi(\mathrm{eV})$ \\
\hline $\mathrm{Pb}(111)$ & Metallic & $0.33 / 0.32$ & $0.28^{a 48}$ & $3.8 / 3.8$ & $3.78^{a 48}, 3.83^{a 49}$ \\
$\alpha-\mathrm{PbO}(001)$ & $1.72^{c}$ & $0.34^{c} / 0.20^{c}$ & $0.08^{b 51}$ & $4.5^{c} / 3.6^{c}$ & $3.60^{b 51}$ \\
$\beta-\mathrm{PbO}(100)$ & $2.89^{c}$ & $0.33^{c} / 0.24^{c}$ & $0.13^{a 53}$ & $5.5^{5} / 4.6^{c}$ & - & $4.46^{52}$ \\
$\beta-\mathrm{PbO}_{2}(110)$ & Metallic & $0.77 / 0.55$ & - & $7.5 / 6.9$ & - & - \\
$\alpha-\mathrm{Bi}_{2} \mathrm{O}_{3}(010)$ & 3.18 & $0.37 / 0.37$ & $0.26^{a 34}, 0.38^{b 51}$ & $5.5 / 4.9$ & $4.1^{b 51}$ & $4.82^{52}$ \\
$\mathrm{SnO}_{2}(110)$ & 2.18 & $1.26 / 1.04$ & $1.04^{a 54}, 1.31^{b 51}$ & $7.5 / 6.6$ & $7.48^{b 51}$ & $4.55,^{52} 4.4-5.7^{55}$
\end{tabular}

Functionals: ${ }^{a}$ PBE functional. ${ }^{b}$ PBEsol functional. ${ }^{c}$ D3 dispersion correction applied.

has been observed for $\mathrm{SnO}_{2}$ in a DBP. ${ }^{12}$ Finally, in agreement with the computational study by Lei and Chen, ${ }^{34}$ the (010) surface with terminating oxygen atoms was determined to be the most stable cleaved model for $\alpha-\mathrm{Bi}_{2} \mathrm{O}_{3}$.
The work function is a measure of the ease of electron removal from the valence band of the material to the vacuum. Our HSE06 computed values (see Table 1) for $\mathrm{Pb}$ and $\alpha$-PbO match experimental values well, and the PBE computed work 
function matches another report using the PBEsol functional. ${ }^{51}$ For $\alpha-\mathrm{Bi}_{2} \mathrm{O}_{3}(010)$, both computed values are higher than previously reported, ${ }^{51}$ but match better with experiment. $\mathrm{PbO}_{2}$ and $\mathrm{SnO}_{2}$ (110) predict much higher work functions than experimentally observed, but match previous theoretical works for $\mathrm{SnO}_{2}(110) .{ }^{51}$ The reason for this disparity is likely due to the experimental ease of formation of oxygen vacancies on these surfaces, which has been found to raise the Fermi level closer to the conduction band, resulting in lower work functions. ${ }^{63}$ Despite this, the trends between experiment and theory remain consistent, and high values for the surface work functions of $\mathrm{PbO}_{2}$ and $\mathrm{SnO}_{2}(110)$ remain.

With respect to chemical reactivity, the very low work function value obtained for $\mathrm{Pb}(111)$ indicates that the surface is easily oxidised, in accordance with the metallic nature of this material. All other surfaces are harder to oxidise. While the inclusion of $\mathrm{O}$ p-states to the Fermi surface will increase the work function compared to $\mathrm{Pb}$ (see Fig. 6 for bulk model density of states, $\mathrm{ESI} \dagger$ for the surface model equivalents), all oxide surfaces retain a significant metal contribution bar $\beta-\mathrm{PbO}_{2}$ and $\mathrm{SnO}_{2}$ which are almost entirely composed of $\mathrm{O}$ p-states, and thus return the largest surface work functions of the set. We observe that the work function for $\alpha-\mathrm{PbO}(001)$ is lower than that for $\alpha-\mathrm{Bi}_{2} \mathrm{O}_{3}(010)$, suggesting the former is more readily oxidised than the latter. $\beta-\mathrm{PbO}(100)$ is also narrowly smaller than $\alpha-\mathrm{Bi}_{2} \mathrm{O}_{3}(010)$. Overall, the lower work functions observed for $\mathrm{Pb}$ and the $\mathrm{PbO}$ polymorphs suggest these surfaces can be more readily oxidised than the other systems in the text set, which in turn may account for why Pb-based compounds aide the reduction of aldehyde fragments to form carbonaceous material at the burning surface in DBPs.

Thus a clear picture emerges from the computational modelling work performed on the bulk models and bare surfaces. $\mathrm{Pb}$ and $\mathrm{PbO}$ present lower (more stable) surface energies, lower surface work functions and smaller electronic band gaps, indicating these materials possess a greater chemical reactivity compared to the less stable $\mathrm{PbO}_{2}$ and the $\mathrm{Pb}$-free ballistic modifiers included in the test group.

\section{Carbon binding study to surface models}

An important feature of the catalytic activity of ballistic modifiers in DBPs is their propensity to support a large amount of amorphous carbon at the burning surface. In particular, a compelling theory is that the formation of this carbon soot layer, and its subsequent loss with increasing pressure, is responsible for the super-rate and plateau/mesa burning mechanisms in DBPs. ${ }^{18,27}$ To test this hypothesis, layers of amorphous carbon have been deposited onto each of the most stable surface models identified in the previous section. The aim is to investigate the interaction between a carbon layer and the surface; if the bare surface remains intact then it becomes possible to define an adsorption energy (see ESI $\dagger$ ). Owing to the complex nature of the amorphous layer it is not expected that the true energy minima will be obtained, but any variation in interaction across the model surfaces should yield further critical insight into the enhanced catalytic behaviour observed for the Pb-containing modifiers.
Initial adsorption models, constructed in order to adsorb equivalent amounts of carbon to each surface (ca. 1 carbon atom per $1.4 \AA^{2}$ of surface area) are presented in the ESI. $\dagger$ The output structures obtained and binding energies obtained where possible are shown in Fig. 8; optimised properties are also displayed in the ESI. $\dagger$

As observed from the negative binding energies in Fig. 8, binding of a carbon layer to all surfaces results in favourable

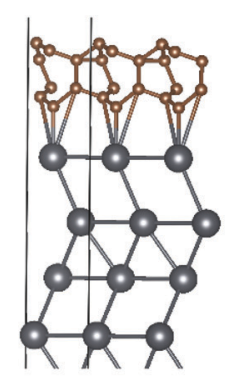

$\mathrm{Pb}(111)$ $-0.09 \mathrm{eV} / \AA^{2}$

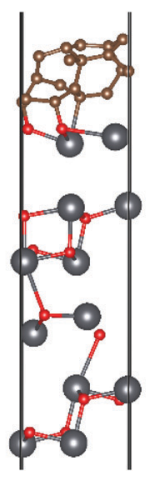

$\beta-\mathrm{PbO}(100)$

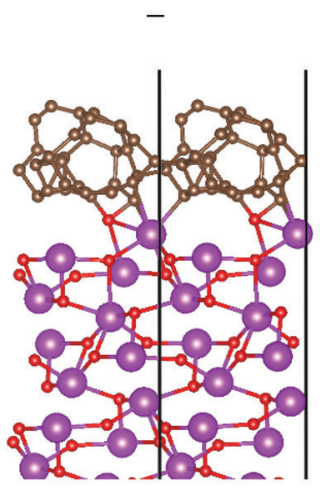

$\alpha-\mathrm{Bi}_{2} \mathrm{O}_{3}(010)$

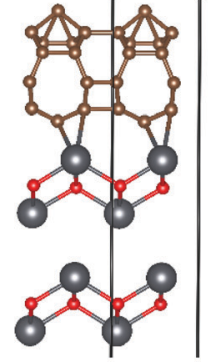

$\alpha-\mathrm{PbO}(001)$

$-0.06 \mathrm{eV} / \AA^{2}$

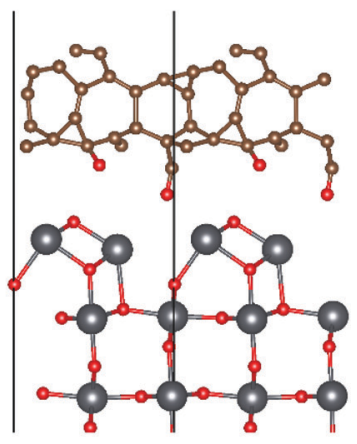

$\beta-\mathrm{PbO}_{2}(110)$

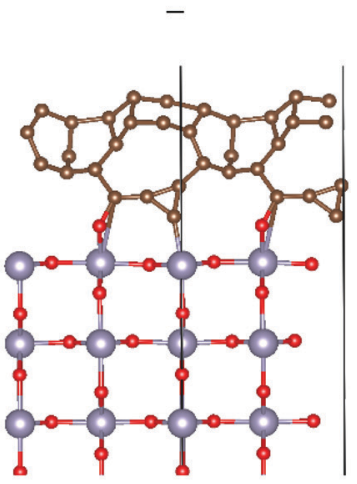

$\mathrm{SnO}_{2}(110)$
$-0.18 \mathrm{eV} / \AA^{2}$

$-0.29 \mathrm{eV} / \AA^{2}$

Fig. 8 Optimised adsorption models and energies for binding amorphous carbon to bare metal and metal oxide surfaces. 
adsorption interactions. For $\alpha-\mathrm{PbO}(001)$ and $\mathrm{Pb}(111)$, the absence of any oxygen atoms at the binding surface means that only relatively weak $\mathrm{Pb}-\mathrm{C}$ bonds can form, and it is likely that the carbon layer would be easily detached. These models therefore appear to support the build-up and reduction of an amorphous carbon layer, as postulated in the carbon soot theory to account for all three DBP burn rate effects summarised in Fig. $1 .^{18}$ The $\beta$-PbO and $\beta-\mathrm{PbO}_{2}$ surfaces have more accessible oxygen sites that take part in binding to carbon, and structural distortion effects are observed in both which render the calculation of carbon binding energies unreliable. For the latter model the oxygen atoms are ripped out of the surface to form part of the carbon matrix. While the removal of oxygen atoms will introduce defects and likely increase the reactivity of $\mathrm{Pb}$ sites, it seems unlikely that this model could support stable attachment of a carbon layer. Interestingly, while $\mathrm{SnO}_{2}(110)$ and $\mathrm{PbO}_{2}(110)$ are structurally very similar, the $\mathrm{SnO} 2$ surface model remains intact upon carbon binding, again demonstrating the significantly stronger $\mathrm{Sn}-\mathrm{O}$ bonds compared to $\mathrm{Pb}-\mathrm{O} .^{62}$ Similarly, carbon binding to $\alpha-\mathrm{Bi}_{2} \mathrm{O}_{3}(010)$ appears to leave the surface largely intact, and strong $\mathrm{C}-\mathrm{O}$ interactions results in a relatively strong surface attachment. With respect to their experimental action as ballistic modifiers, this likely explains why $\mathrm{SnO}_{2}$ is observed to build up large layers of carbon matter, sustaining super-rate burning but failing to achieve plateau/ mesa-rate burning through the loss of this layer. ${ }^{12}$ In the case of $\alpha-\mathrm{Bi}_{2} \mathrm{O}_{3}$ (and it's respective acidic salts), addition to double-base propellants results in accelerated burning at low pressures, but fails to achieve plateau burning at the low pressures of lead salts. ${ }^{64-66}$

\section{Conclusions}

There is a pressing need to find non-toxic replacements for lead-based ballistic modifiers in double-base propellant rocket systems. Consensus in the literature points towards decomposition of the ballistic modifier to form metal-containing clusters at the burning surface in the propellant combustion zone; these clusters act as catalytic sites to seed decomposition of the nitrate ester fuel. As no suitable lead-free alternatives exist, this study reports on a first principles simulation study to identify key metrics found for lead-based compounds.

In summary, bulk electronic band structures, surface electronic properties, surface energies and surface work functions have been investigated to gain an understanding into the electronic properties of the systems studied. A carbon-binding study has also been performed to investigate the interaction between a carbon layer and the bare surface. For the bulk materials, the lead-based systems ( $\mathrm{Pb}, \alpha-\mathrm{PbO}$, and $\left.\beta-\mathrm{PbO}_{2}\right)$ present smaller electronic band gaps, suggesting a greater chemical reactivity, than the lead-free alternatives. The surface energies obtained for each model, which are indicative of the relative ease for each material to form clusters with stable faces at a gas/solid reactive interface, indicate that the presence of lead renders the bulk models more energetically favourable to cleave. Calculated surface work functions suggest that the lead-containing models are easier to oxidise than the lead-free models. Intriguingly, literature reports on $\mathrm{Bi}_{2} \mathrm{WO}_{6}$, introduced at the start of this paper as the first lead-free material capable of supporting plateau rate burning (at higher gas pressures than for the Pb-based salts), suggest low surface energies, a band gap smaller than that reported herein for $\mathrm{Bi}_{2} \mathrm{O}_{3}$, and a surface work function in the upper range of materials reported here. ${ }^{67}$ Finally, the carbon-binding study has revealed weak binding to the $\mathrm{Pb}$ and $\alpha$-PbO surfaces, destruction of the $\beta-\mathrm{PbO}$ and $\beta-\mathrm{PbO}_{2}$ surface, and stronger binding to the $\alpha-\mathrm{Bi}_{2} \mathrm{O}_{3}$ and $\mathrm{SnO}_{2}$ systems. This suggests that the first two systems alone are capable of supporting the growth and destruction of the amorphous carbon layer postulated to account for the modified burn-rate properties inferred by the lead-based additives. Taken together, this first principles study has highlighted important metrics that may cast light on the enhanced ballistic modifier properties offered by the current materials used, which we hope provides guidance in the on-going search to find lead-free alternatives.

\section{Computational methods}

\section{Bulk models and surfaces: CRYSTAL17}

In order to make use of hybrid DFT for accurate electronic band structures, localised basis set calculations have been performed using the ab initio periodic CRYSTAL17 code. Pseudopotentials or all-electron atom-centered Gaussian-type functions are used for basis sets through the standard LCAO method. ${ }^{68}$ An allelectron basis set was used for $\mathrm{O}(8-411 \mathrm{~d} 1$ in the notation used by CRYSTAL), ${ }^{69,70}$ and for $\mathrm{Pb}, \mathrm{Bi}$ and $\mathrm{Sn}$ the scalar-relativistic small-core pseudopotential developed by Metz, Stoll and Dolg ${ }^{71}$ was employed along with $22(\mathrm{~Pb}, \mathrm{Sn})$, and 23 (Bi) valence electrons treated explicitly. For $\mathrm{Bi}_{2} \mathrm{O}_{3}, \mathrm{PbO}_{2}$ and $\mathrm{SnO}_{2}$ the valence electrons were described using $\mathrm{Bi}-4411-411-411 \mathrm{~d},{ }^{72}$ Sn-411-51d and Pb-6111-51d notations respectively. ${ }^{73}$ For $\mathrm{Pb}$ and $\mathrm{PbO}$, a cc-pVDZ (double zeta quality) basis set was required to describe the valence electrons due to the metal/layered nature of the structures. ${ }^{74}$

For the bulk systems full optimisation of the atomic positions and lattice parameters was performed (only atomic positions were optimised for layered $\mathrm{PbO}$ ). Tested functionals were the pure GGA PBE, ${ }^{75}$ and the B3LYP, ${ }^{76,77} \mathrm{PBE} 0,{ }^{78} \mathrm{~B} \mathrm{PW}^{77,79}$ and HSE $06^{80}$ hybrid functionals. The Grimme D3 dispersion correction scheme (DFT-D3) ${ }^{81}$ has been tested for all calculations, but was found to overbind the monoclinic $\alpha-\mathrm{Bi}_{2} \mathrm{O}_{3} b$-axis, so was not applied to its surface and bulk models. Convergence of the k-point grid was considered for energy differences of $10^{-6}$ a.u., resulting in a Monkhorst-Pack shrinking factor ${ }^{82}$ of 14 for $\mathrm{PbO}_{2}$, $\mathrm{SnO}_{2}$ and $\mathrm{PbO}, 8$ for $\mathrm{Bi}_{2} \mathrm{O}_{3}$, and 16 for $\mathrm{Pb}$. To describe the metallic nature of $\mathrm{Pb}$, the Gilat net ${ }^{83}$ was doubled to 32 , and a Fermi smearing temperature of 0.01 a.u. was applied. Other computation conditions include the evaluation of the bielectronic Coulomb and exchange contributions to the Fock matrix are controlled by five overlap criteria, set in this study to $10^{-7}, 10^{-7}$, $10^{-7}, 10^{-7}$, and $10^{-14}$ in atomic units. ${ }^{83,84}$ Convergence criteria 
was determined from the root-mean-square and absolute value of both the gradients and estimated displacements. ${ }^{83}$ In addition, the energy threshold criteria between two successive optimisation steps is set to $10^{-7}$ a.u.

All conditions defined above for the bulk systems were maintained for optimising surfaces in CRYSTAL. 2D periodic boundary conditions were imposed, such that periodicity is interrupted in the $z$-direction. ${ }^{68}$ The only surfaces considered were Tasker-type surfaces, where the bulk lattice is cut to expose non-polar symmetric top and bottom surfaces that maintain the stoichiometry of the host crystal. ${ }^{85}$ For the surfaces, atomic positions only were optimised. The surface energies were computed in the standard way, and surface work functions were computed following the methodology of Doll (see ESI $\dagger)^{86}$

\section{Carbon binding model: CASTEP19}

These simulations were performed using the plane-wave DFT code CASTEP, version 19.1.1. ${ }^{87}$ The GGA PBE functional ${ }^{75}$ was used for all systems, with an energy cutoff of $800 \mathrm{eV}$ for all metal oxides, and $350 \mathrm{eV}$ for $\mathrm{Pb}$, so that convergence was achieved to within $2 \mathrm{meV}$ per atom. Ultrasoft pseudopotentials ${ }^{88}$ were generated "on the fly." For the bulk systems, a Monkhorst-Pack scheme was set such that $k$-point spacings were less than $0.05 \AA^{-1}$. The optimisation convergence tolerances for force, stress, ionic displacement, and energy were $0.01 \mathrm{eV} \AA^{-1}, 0.02 \mathrm{GPa}, 0.005 \AA$, and $5 \times 10^{-6} \mathrm{eV}$ per atom, respectively, with SCF convergence between two cycles of $1 \times 10^{-8} \mathrm{eV}$. For $\mathrm{PbO}_{2}$ and $\mathrm{Pb}$ systems a temperature smearing of $0.1 \mathrm{eV}$ was applied. Atomic positions only were optimised. Monkhorst-Pack $k$-point spacings for surfaces were $6 \times 3 \times 1$ for $\beta-\mathrm{PbO}_{2}$ and $\mathrm{SnO}_{2}(110), 5 \times 5 \times 1$ for $\alpha-\mathrm{PbO}(001), 4 \times 4 \times 1$ for $\beta-\mathrm{PbO}(100), 14 \times 14 \times 1$ for $\mathrm{Pb}(111)$, and $4 \times 5 \times 1$ for $\alpha-\mathrm{Bi}_{2} \mathrm{O}_{3}(010)$. The non-periodic $z$-direction for the surfaces was modelled with a vacuum of $20 \AA$ for all surfaces to fit in the carbon layer. The quantity of carbon added to each surface was calculated to maintain a consistent $c a$. 1 carbon atom per $1.4 \AA^{2}$ of surface area across all models. All systems were tested with the Tkatchenko-Scheffler dispersion correction, ${ }^{89}$ which was applied to the layered $\mathrm{PbO}$ system to optimise the atomic positions.

\section{Conflicts of interest}

There are no conflicts to declare.

\section{Acknowledgements}

All authors kindly acknowledge Gregory W. Drake (U.S. Army Futures Command CCDC-AvMC, Redstone Arsenal, USA) for helpful discussions. Research was sponsored by the Army Research Office and was accomplished under Cooperative Agreement Number W911NF-19-2-0288. The views and conclusions contained in this document are those of the authors and should not be interpreted as representing the official policies, either expressed or implied, of the Army Research Office or the U.S. Government. The U.S. Government is authorized to reproduce and distribute reprints for Government purposes notwithstanding any copyright notation herein. This work has made use of the resources provided by EaSTCHEM Research Computing Facility and the Edinburgh Compute and Data Facility (ECDF) (http://www. ecdf.ed.ac.uk/). We also gratefully acknowledge the UK Materials and Molecular Modelling Hub for computational resources, which is partially funded by EPSRC (EP/P020194/1).

\section{References}

1 H. Shekhar, Cent. Eur. J. Energ. Mater., 2012, 9, 353-364.

2 H. Austruy, in Solid Rocket Propulsion Technology, ed. A. Davenas, Elsevier Ltd, 1993, pp. 369-413.

3 N. Kubota, Propellants and Explosives: Thermochemical Aspects of Combustion, Wiley-VCH Verlag GmbH \& Co. KGaA, Weinheim, Germany, 2015.

4 D. R. Greatrix, Powered Flight: The Engineering of Aerospace Propulsion, Springer, London, London, 2012, pp. 323-379.

5 N. Kubota, T. J. Ohlemiller, L. H. Caveny and M. Summerfield, Symp. Combust., 1975, 15, 529-537.

6 N. Kubota, Symp. Combust., 1979, 17, 1435-1441.

7 G. Lengellé, J. Brulard and H. Moutet, Symp. Combust., 1977, 16, 1257-1269.

8 N. Kubota, T. J. Ohlemiller, L. H. Caveny, J. And and M. Summerfield, AIAA J., 1974, 12, 1709.

9 M. Farber and R. D. Srivastava, Combust. Flame, 1978, 31, 309-323.

10 H. Singh and R. K. Rao, Proc. Indiana Acad. Sci., 1984, 93, 93-97.

11 D. J. Hewkin, J. A. Hicks, J. Powling and H. Watts, Combust. Sci. Technol., 1971, 2, 307-327.

12 A. P. Denisyuk and L. A. Demidova, Combust., Explos. Shock Waves, 2004, 40, 311-318.

13 Y. Wang, Q.-L. Yan, T. An, B. Chen, Y.-P. Ji, W. Wang and F. Zhao, J. Energ. Mater., 2018, 15, 376-390.

14 T. An, F.-Q. Zhao, Q.-L. Yan, Y.-J. Yang, Y.-J. Luo, J.-H. Yi and W.-L. Hong, Propellants, Explos., Pyrotech., 2018, 43, 1087-1095.

15 Lead REACH Consortium, https://ila-reach.org/.

16 Q. L. Yan, F. Q. Zhao, K. K. Kuo, X. H. Zhang, S. Zeman and L. T. DeLuca, Prog. Energy Combust. Sci., 2016, 57, 75-136.

17 T. Wei, Y. Zhang, K. Xu, Z. Ren, H. Gao and F. Zhao, RSC $A d v ., 2015$, 5, 70323.

18 L. R. Warren, Z. Wang, C. R. Pulham and C. A. Morrison, Propellants, Explos., Pyrotech., 2020, 45, DOI: 10.1002/ prep.202000167.

19 G. Lengelle, A. Bizot, J. Duterque and J. F. Trubert, Fundamentals of Solid-Propellant Combustion, AIAA, 1984, vol. 90, pp. 361-407.

20 B. B. de Schor and J. E. Toni, Thermochim. Acta, 1978, 27, 347-356.

21 N. P. Suh, G. F. Adams and C. Lenchitz, Combust. Flame, 1974, 22, 289-293.

22 A. P. Denisyuk, T. M. Kozyreva and V. G. Khubaev, Combust., Explos. Shock Waves, 1975, 11, 271-273. 
23 K. Gavrichev, A. Bolshakov, D. Kondakov, A. Khoroshilov and S. Denisov, J. Therm. Anal. Calorim., 2008, 92, 857-863.

24 H. Singh and K. R. K. Rao, Combust. Flame, 1988, 71, 205-213.

25 L. Shufen, Combust. Sci. Technol., 1998, 133, 395-401.

26 J. Sharma, G. B. Wilmot, A. A. Campolattaro and F. Santiago, Combust. Flame, 1991, 85, 416-426.

27 C. Youfang, Propellants, Explos., Pyrotech., 1987, 12, 209-214.

28 R. J. Hill, Acta Crystallogr., Sect. C: Cryst. Struct. Commun., 1985, 41, 1281-1284.

29 W. B. White, F. Dachille and R. Roy, J. Am. Ceram. Soc., 1961, 44, 170-174.

30 J. Moreau, J. M. Kiat, P. Gamier and G. Calvarin, Phys. Rev. B: Condens. Matter Mater. Phys., 1989, 39, 296-299.

31 J. Haines and J. M. Lé, Phys. Rev. B: Condens. Matter Mater. Phys., 1997, 55, 11144-11154.

32 J. Haines, J. M. Léger and O. Schulte, J. Phys.: Condens. Matter, 1996, 8, 1631-1646.

33 G. Malmros, Acta Chem. Scand., 1970, 24, 384-396.

34 Y. H. Lei and Z. X. Chen, J. Chem. Phys., 2013, 138, 054703.

35 D. J. Payne, R. G. Egdell, W. Hao, J. S. Foord, A. Walsh and G. W. Watson, Chem. Phys. Lett., 2005, 411, 181-185.

36 D. J. Payne, G. Paolicelli, F. Offi, G. Panaccione, P. Lacovig, G. Beamson, A. Fondacaro, G. Monaco, G. Vanko and R. G. Egdell, J. Electron Spectrosc. Relat. Phenom., 2009, 169, 26-34.

37 B. Thangaraju and P. Kaliannan, Semicond. Sci. Technol, 2000, 15, 542-545.

38 R. C. Keezer, D. L. Bowman and J. H. Becker, J. Appl. Phys., 1968, 39, 2062-2066.

39 D. J. Payne, R. G. Egdell, D. S. L. Law, P. A. Glans, T. Learmonth, K. E. Smith, J. Guo, A. Walsh and G. W. Watson, J. Mater. Chem., 2007, 17, 267-277.

40 J. C. Schottmiller, J. Appl. Phys., 1966, 37, 3505-3510.

41 J. Deng and Z. Y. Zhao, Comput. Mater. Sci., 2018, 142, 312-319.

42 T. P. Debies and J. W. Rabalais, Chem. Phys., 1977, 20, 277-283.

43 H. Cheng, B. Huang, J. Lu, Z. Wang, B. Xu, X. Qin, X. Zhang and Y. Dai, Phys. Chem. Chem. Phys., 2010, 12, 15468-15475.

44 D. Fröhlich, R. Kenklies and R. Helbig, Phys. Rev. Lett., 1978, 41, 1750-1751.

45 F. Ma, Y. Jiao, G. Gao, Y. Gu, A. Bilic, S. Sanvito and A. Du, ACS Appl. Mater. Interfaces, 2016, 8, 25667-25673.

46 A. Walsh, D. J. Payne, R. G. Egdell and G. W. Watson, Chem. Soc. Rev., 2011, 40, 4455-4463.

47 A. Walsh and G. W. Watson, J. Solid State Chem., 2005, 178, 1422-1428.

48 D. Yu and M. Scheffler, Phys. Rev. B: Condens. Matter Mater. Phys., 2004, 70, 1-8.

49 B. Sun, P. Zhang, Z. Wang, S. Duan, X.-G. Zhao, X. Ma and Q.-K. Xue, Phys. Rev. B: Condens. Matter Mater. Phys., 2008, 78, 035421.

50 H. B. Michaelson, J. Appl. Phys., 1977, 48, 4729.

51 Y. Hinuma, T. Toyao, T. Kamachi, Z. Maeno, S. Takakusagi, S. Furukawa, I. Takigawa and K.-I. Shimizu, J. Phys. Chem. C, 2018, 122, 29435-29444.
52 Y. Xu and M. A. A. Schoonen, Am. Mineral., 2000, 85, 543-556.

53 J. Fang Lv, C. Lin Fan, X. Tong, Y. Xing Zheng and X. Li, Appl. Surf. Sci., 2019, 470, 135-142.

54 J. Oviedo and M. J. Gillan, Surf. Sci., 2000, 463, 93-101.

55 A. Klein, C. Körber, A. Wachau, F. Säuberlich, Y. Gassenbauer, R. Schafranek, S. P. Harvey and T. O. Mason, Thin Solid Films, 2009, 518, 1197-1203.

56 J. Wang and S. Q. Wang, Surf. Sci., 2014, 630, 216-224.

57 Y. Duan, Phys. Rev. B: Condens. Matter Mater. Phys., 2008, 77, $1-22$.

58 F. Labat, P. Baranek and C. Adamo, J. Chem. Theory Comput., 2008, 4, 341-352.

59 M. Ramamoorthy, D. Vanderbilt and R. D. King-Smith, Phys. Rev. B: Condens. Matter Mater. Phys., 1994, 49, 16721-16727.

60 R. A. Evarestov and Y. F. Zhukovskii, Surf. Sci., 2013, 608, 226-240.

61 U. Diebold, Surf. Sci. Rep., 2003, 48, 53-229.

62 T. L. Cottrell, The Strengths of Chemical Bonds, Butterworths, London, 2nd edn, 1958.

63 K. T. Butler, J. Buckeridge, C. Richard, A. Catlow and A. Walsh, Phys. Rev. B: Condens. Matter Mater. Phys., 2014, 89, 115320.

64 R. M. Jorge and A. A. M. F. Filho, J. Aerosp. Technol. Manage., 2019, 11, 15-18.

65 S. B. Thompson, J. L. Goodwin and A. T. Camp, US Pat., US005652409A, 1997.

66 J. Neidert and R. E. Askins, US Pat., US5372070A, 1994.

67 F. Opoku, K. K. Govender, C. G. C. E. van Sittert and P. P. Govender, Appl. Surf. Sci., 2018, 427, 487-498.

68 R. Dovesi, A. Erba, R. Orlando, C. M. Zicovich-Wilson, B. Civalleri, L. Maschio, M. Rérat, S. Casassa, J. Baima, S. Salustro and B. Kirtman, Wiley Interdiscip. Rev.: Comput. Mol. Sci., 2018, 8, 1-36.

69 T. Bredow, K. Jug and R. A. Evarestov, Phys. Status Solidi B, 2006, 243, 10-12.

70 M. D. Towler, N. L. Allan, N. M. Harrison, V. R. Saunders, W. C. Mackrodt and E. Apra, Phys. Rev. B: Condens. Matter Mater. Phys., 1994, 50, 5041-5054.

71 B. Metz, H. Stoll and M. Dolg, J. Chem. Phys., 2000, 113, 2563-2569.

72 E. Heifets, E. A. Kotomin, A. A. Bagaturyants and J. Maier, J. Phys. Chem. Lett., 2015, 6, 2847-2851.

73 G. Sophia, P. Baranek, C. Sarrazin, M. Rérat and R. Dovesi, Phase Transitions, 2013, 86, 1069-1084.

74 K. A. Peterson, J. Chem. Phys., 2003, 119, 11099-11112.

75 J. P. Perdew, K. Burke and M. Ernzerhof, Phys. Rev. Lett., 1996, 77, 3865-3868.

76 C. Lee, W. Yang and R. G. Parr, Phys. Rev. B: Condens. Matter Mater. Phys., 1988, 37, 785.

77 A. D. Becke, J. Chem. Phys., 1993, 98, 5648-5652.

78 C. Adamo and V. Barone, J. Chem. Phys., 1999, 110, 6158-6170.

79 J. P. Perdew and W. Yue, Phys. Rev. B: Condens. Matter Mater. Phys., 1986, 33, 8800-8802. 
80 J. Heyd, G. E. Scuseria and M. Ernzerhof, J. Chem. Phys., 2003, 118, 8207-8215.

81 S. Grimme, J. Antony, S. Ehrlich and H. Krieg, J. Chem. Phys., 2010, 132, 154104.

82 H. J. Monkhorst and J. D. Pack, Phys. Rev. B: Solid State, 1976, 13, 5188.

83 R. Dovesi, V. R. Saunders, C. Roetti, R. Orlando, C. M. Zicovich-Wilson, F. Pascale, B. Civalleri, K. Doll, N. M. Harrison, I. J. Bush, P. D’Arco, M. Llunel, M. Causà, Y. Noël, L. Maschio, A. Erba, M. Rérat and S. Casassa, CRYSTAL17 User's Manual, University of Torino, Torino, 2017.
84 C. Pisani, R. Dovesi and C. Roetti, Hartree-Fock Ab Initio Treatment of Crystalline Systems, Springer-Verlag, 1988.

85 P. W. Tasker, J. Phys. C: Solid State Phys., 1979, 12, 4977-4984. 86 K. Doll, Surf. Sci., 2006, 600, L321-L325.

87 S. J. Clark, M. D. Segall, C. J. Pickard Ii, P. J. Hasnip, M. I. J. Probert, K. Refson and M. C. Payne, Z. Krist., 2005, 220, 567-570.

88 D. Vanderbilt, Phys. Rev. B: Condens. Matter Mater. Phys., 1990, 41, 7892-7895.

89 A. Tkatchenko and M. Scheffler, Phys. Rev. Lett., 2009, 102, 073005. 